\title{
Possible corrosion-mechanical damages of welded joints and their impact on long-term operation of equipment
}

\author{
Mikhail Antonov ${ }^{1}$, Aleksandr Kalyutik ${ }^{1, *}$, Yury Karyakin ${ }^{1}$, Alexandr Arzhaev ${ }^{2}$, Alexey Arzhaev ${ }^{2}$, Valentin Makhanev $^{2}$ \\ ${ }^{1}$ Peter the Great Sankt-Petersburg Polytechnic University, Sankt-Petersburg, Russia \\ ${ }^{2}$ LLE "SPE "DIAPROK”, Moscow, Russia
}

\begin{abstract}
Specific features of corrosion-mechanical damages of primary circuit header to steam generator vessel branch welds at VVER-440/1000 NPPs and their influence on safety and economic efficiency during long-term operation are analysed.
\end{abstract}

One of serious issues during VVER-440/1000 NPPs operation are damages of primary circuit header to steam generator (SG) vessel branch welds. The welds under consideration are conventionally indicated as $\mathbf{S S \# 2 3}$ (VVER-440) and SS\#111 (VVER-1000) which corresponds to both "hot" and "cold" SG headers.

The considered units of SGs have design differences: SS\#23 - Figure 1 from [1] and SS\#111 - Figure 2 from [2]. A typical view of the "pocket" in the area of the SS\#111 is shown in the right part of Figure 2.

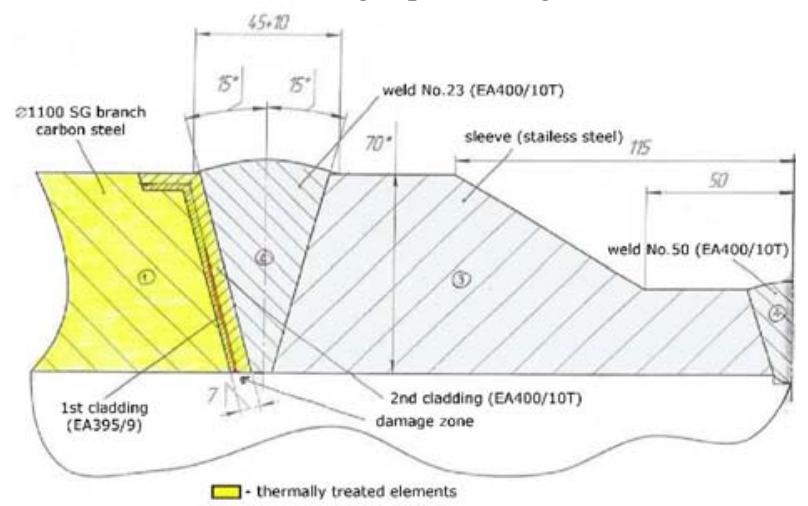

Fig.1. Sketch of the SS\#23 zone of primary circuit header to SG PGV-4M vessel branch weld.

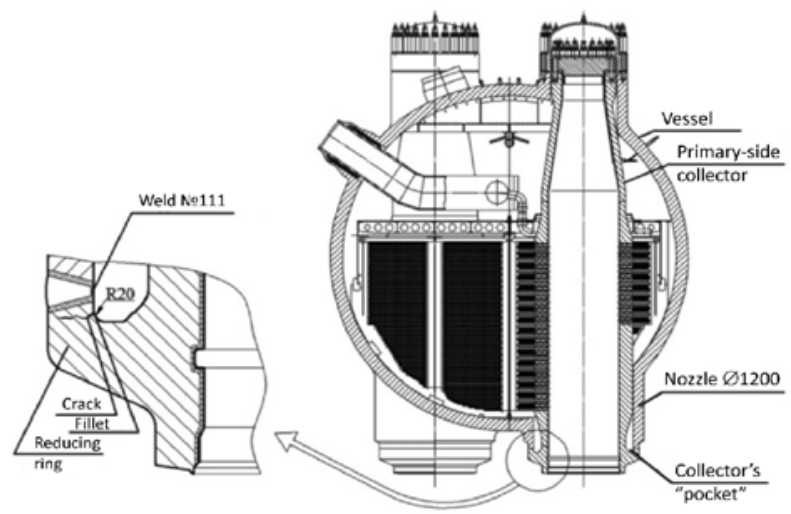

Fig.2. Steam generator PGV-1000M [2].
All SG branches connected to headers are oblique ones having long and short forming lines.

Damage to SS\#23 and SS\#111 was initiated on the inner surface from the "pockets" under corrosion impact of the secondary circuit coolant. In the "pockets" of SGs (Figures 1 and 2), the parameters of the water chemistry may differ for the worse with accumulation of corrosion products and increased content of impurities.

SS\#23 is a dissimilar weld. First SS\#23 damages have been revealed at Novovoronezh NPP Unit No. 3 in the year 2007 after 30 years of operation. Similar damage was subsequently detected at many VVER-440 NPP units in the Russian Federation, as well as in the Czech Republic, Armenia and other countries.

During investigation of the nature and causes of SS\#23 damage at unit No. 3 of Novovoronezh NPP, it was found that in all cases the main cause of damage associated with the formation of cracks in the first layer of cladding (surfacing), made by electrodes EA-395/9, heat treated after welding and being in contact with the coolant during operation (Figure 3).

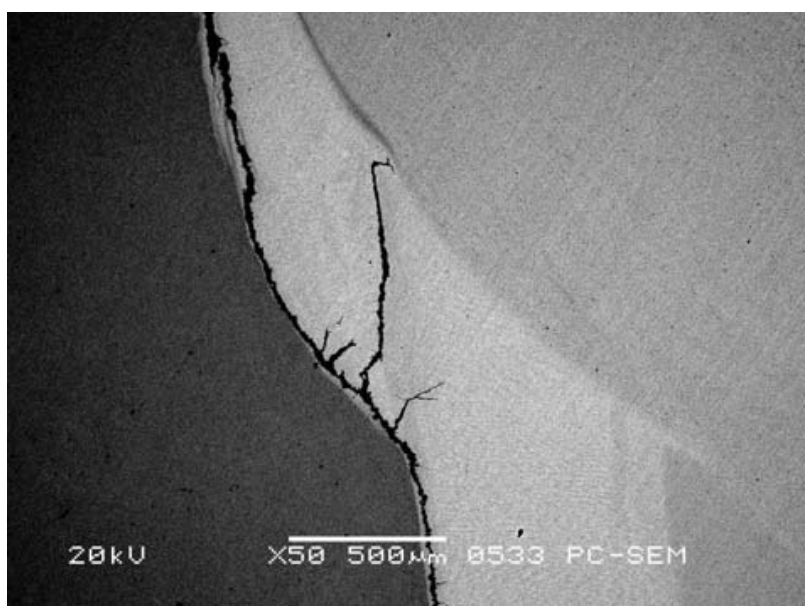

Fig.3. Damage to the first layer of cladding welded by electrode EA 395/9 (Figure 1).

\footnotetext{
* Corresponding author: aa kalyutik@spbstu.ru
} 
In almost all cases, the damage was initiated from the inner surface of the welded joint and grew along the zone near the fusion line of the first layer of surfacing by mechanism of intergranular corrosion [3, 4]. According to the results of later studies, the damage mechanism was clarified as intergranular stress corrosion cracking (IGSCC) [1].

Formation of circumferential cracks along the entire perimeter of the welded joint created potential for guillotine destruction of the SS\#23 zone.

The detected circumferential cracks were repaired by $100 \%$ removing the defective ones and welding a new welded joint.

To ensure the operability of SGs of NPP units with VVER-440 for up to 60 years in Russia has been developed an effective set of compensating measures, the use of which on-site has allowed to eliminate the main cause of SCC in areas of $\mathbf{S S \# 2 3}$ and provide postrepair conditions for long-term operation of NPP units with VVER-440.

For the first time, SS\#111 damage was detected in 1998 at unit No. 5 of Novovoronezh NPP due to a leak. Subsequently, damages to SS\#111 welding of "hot" and "cold" SG headers were detected at the Russian NPP units (unit No. 5 of Novovoronezh NPP, units No.No.1, 2 and 4 of the Balakovo NPP), as well as at the Ukrainian NPPs (South Ukrainian NPP and Zaporozhye NPP).

The paper analyzes accumulated data that allows to explain the primary damage to SS\#111 by high level of loads caused by the restricted movement of SG along the supports, combined with water chemistry features in the SG "pocket" (Figure 2).

For NPP units under construction and under design, the results of the analysis can be used to minimize the tendency of SS\#111 to damage during long-term operation.

Materials science studies of metal cut from damaged SS\#111 zones revealed corrosion-mechanical damage in form of cracks initiating from the inner surface of the "pocket" in contact with secondary side coolant.

The mechanism of crack initiation and growth in the SS\#111 zones was defined as delayed deformation corrosion cracking [5-7]. Studies performed in Ukraine have confirmed the same nature of damage of defective SS\#111 zones of "hot" and "cold" headers [8]: "comprehensive studies and data obtained earlier suggest that the nature of destruction of welded joints in the steam generators of the South Ukrainian and Zaporozhye NPP is the same, despite the fact that cracks were formed on the "hot" header in the first case, and on the "cold" - in the second".

Due to the complexity of the delayed deformation corrosion cracking process there is no definitive unambiguous conclusion on the determining factors of operational damage to SS\#111 yet.

In [2] based on results of computational substantiation of the strength of the header and its connection zone with the SG branch, using refined threedimensional finite element models and taking into account the main factors (pressure environments of the first and second circuits; temperature field during facility operation at nominal parameters, loads from piping of the main circulation circuit (MCC)), it was noted "power" impact of MCP on the area of damage in combination with improper work of SG supports PG:

"- jamming of the SG supports can lead to high tensile stresses in the welded connection of the input header when the unit is operating at nominal parameters;

- under normal operating conditions, the contribution of forces from the MCP to the stress state of the SS\#111 zone is rather small, however, jamming or improper operation of the SG supports leads to an increase in loads from connected MCP and an increase in tensile stresses in one of the zones with maximum stresses (damage zone), while in the other zone with maximum stresses their level decreases;

- conditions (in terms of mechanical stresses) for damage by the delayed deformation corrosion cracking mechanism may occur during improper operation of SG supports in a "hot" collector."

In the report of JSC OKB "Gidropress" [9] about the SS\#111 zone, it was stated that "the highest level of loading of the zone is realized during hydraulic testing of SG secondary circuit (at the level of yield strength) and when cooling via blowdown lines, and is also possible during improper operation of the SG supports".

Characteristically, the position of the primary damages in the SS\#111 zones of "cold" headers is also close to the so-called "MCC line" as for "hot" headers (Figure 4) both on VVER NPP Units of "small" series, and on VVER NPP Units of the project V-320 (according to JSC NPO "CNIITMASH" reports [6, 10]).

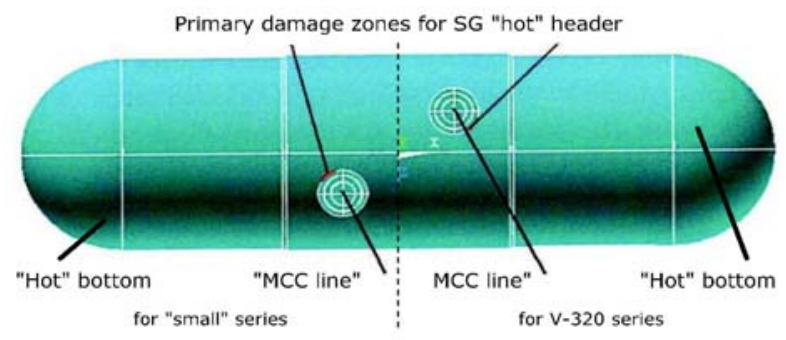

Fig.4. Zones of primary damages for VVER-1000 of "small" series and V-320 series from [11].

This is consistent with the hypothesis that there is a directed mechanical impact of the MCP on the SS\#111 zones, which should be taken as the main factor in the formation and growth of primary cracks in the direction of the "MCC line" (Figures 5-7). Figure 5 shows the caption comments that are common to Figures 5-7.

Other factors (technology of rolling heat exchange tubes, presence of deposits in the "pockets" of SG, actual parameters of the secondary circuit water chemistry, etc.) should be considered as concomitant, despite their possible influence on the rate of undergrowth of cracks by delayed deformation corrosion cracking mechanism.

Table 1 provides information on repairs of the SS\#111 zones at all NPP units with VVER-1000 reactor facility according to $[6,9,12]$ : the intense yellow background highlights the primary damage to the SS\#111 zones of the "hot" headers, and the blue 
background highlights the "cold" headers. The "+" symbols indicate the number of repeated damages in different years. Information about the absence of cracking of the SS\#111 zones at VVER-1000 NPPs was confirmed in the speeches of representatives from Ukraine (Rivne and Khmelnitsky NPPs), Bulgaria (Kozloduy NPP) and the Czech Republic (Temelin NPP) at the WANO MC seminar held in Yerevan (Armenia) in May 2015 [13].
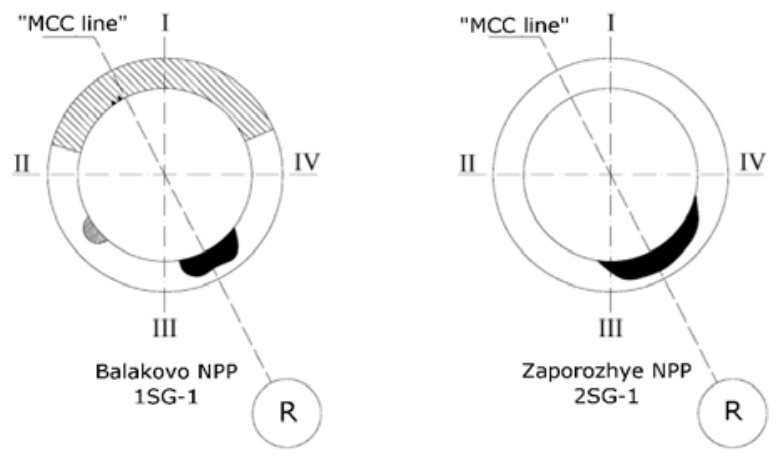

1

primary damage (1st repair)

secondary damage (2nd and other repairs)

(R) - reactor

1 - long forming line (FL) of the ø 1200 SG branch

II - FL of the Ø1200 SG branch near SG "cold" bottom (Figure 4)

III - short FL of the $\varnothing 1200$ SG branch

IV - FL of the $\varnothing 1200$ SG branch near SG "hot" bottom (Figure 4)

"MCC line" connects centers of reactor and each SG header

Fig.5. Zones of primary and repeated defects in SS\#111 of VVER NPP Units of the project V-320 ([2]).
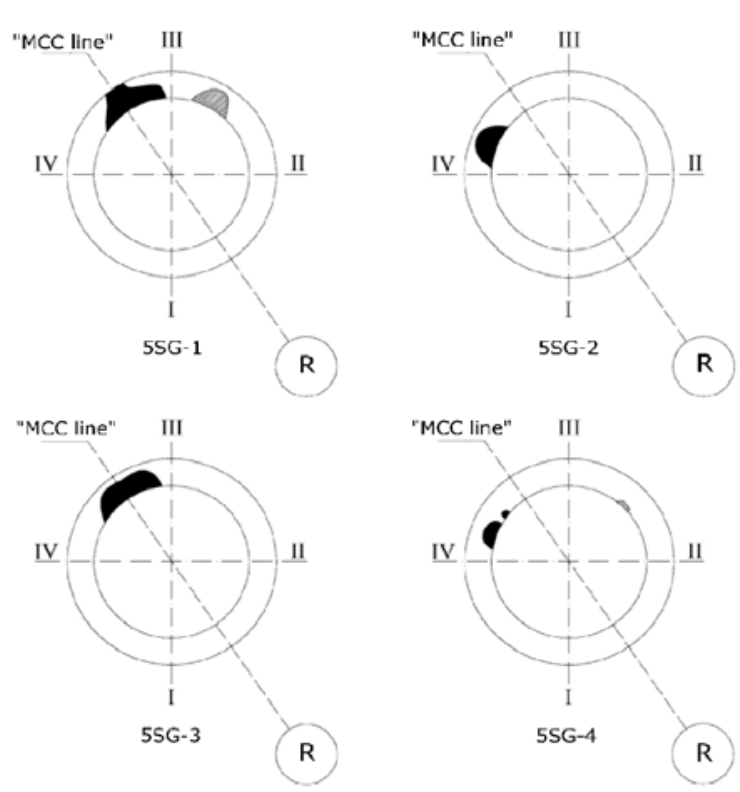

Fig.6. Zones of primary and repeated defects in SS\#111 of the unit No. 5 of Novovoronezh NPP ([2]).
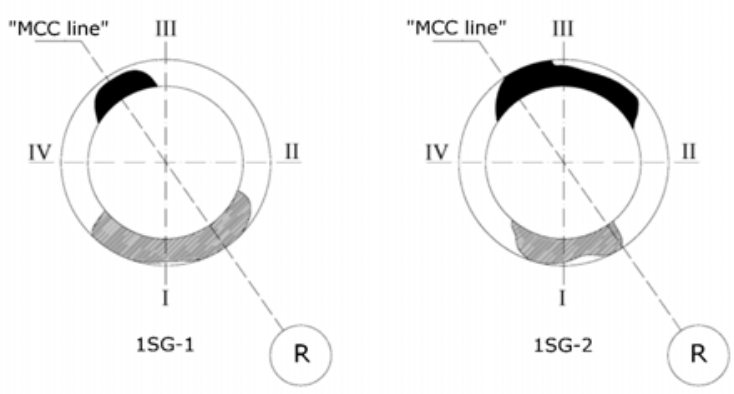

Fig.7. Zones of primary and repeated defects in SS\#111 of the unit No. 1 of South Ukrainian NPP ([2]).

Table 1. Information on repairs of the SS\#111 zones at all NPP units with VVER-1000.

\begin{tabular}{|c|c|c|c|c|c|c|c|c|c|}
\hline \multirow{2}{*}{ NPP } & \multirow{2}{*}{ Unit } & \multicolumn{2}{|c|}{ SG-1 } & \multicolumn{2}{|c|}{ SG-2 } & \multicolumn{2}{|c|}{ SG-3 } & \multicolumn{2}{|c|}{ SG-4 } \\
\hline & & "Hot" & "Cold" & "Hot" & "Cold" & "Hot" & "Cold" & "Hot" & "Cold" \\
\hline Novovoronezh NPP & 5 & n++ & & + & & + & & ++ & \\
\hline \multirow[t]{4}{*}{ Kalinin NPP } & 1 & & & & & & + & & \\
\hline & 2 & & & & & & & & \\
\hline & 3 & & & & & & & & \\
\hline & 4 & & & & & & & & \\
\hline \multirow[t]{4}{*}{ Balakovo NPP } & 1 & ++ & & & & & & & + \\
\hline & 2 & & & ++ & & & & & \\
\hline & 3 & & & & & & & & \\
\hline & 4 & & + & & & & & & \\
\hline \multirow[t]{3}{*}{ Rostov NPP } & 1 & & & & & & & & \\
\hline & 2 & & & & & & & & \\
\hline & 3 & & & & & & & & \\
\hline \multirow[t]{3}{*}{ South Ukrainian NPP } & 1 & t+ & & t+ & & & & & \\
\hline & 2 & & & & & & & & \\
\hline & 3 & $*$ & $* *$ & & & & $* *$ & & \\
\hline \multirow[t]{6}{*}{ Zaporozhye NPP } & 1 & & & & & & & & \\
\hline & 2 & + & + & & + & & & & \\
\hline & 3 & & & & & & & & \\
\hline & 4 & & & & & + & & & \\
\hline & 5 & & & & & & & & \\
\hline & 6 & & & & & & & & \\
\hline
\end{tabular}

Note: at Unit No.3 of South Ukrainian NPP sub-surface flaws were revealed by In-service Inspection [13] and repaired in $2012(*)$ and $2014(* *)$ 
Information on repeated damages of the SS\#111 zones are shown in Table 2: the intense yellow background highlights the primary damage to the SS\#111 zones of the "hot" headers, (the cases of repeated damages are highlighted in light yellow background), and the blue background highlights the "cold" headers. Through wall damage is marked with the " $\mathbf{\Delta}$ "symbol.

Table 2. Information on repeated damages of the SS\#111 zones.

\begin{tabular}{|c|c|c|c|c|c|c|c|c|c|c|c|c|c|c|c|c|c|c|c|c|}
\hline NPP & NoSG & Replaced & 1998 & 1999 & 2000 & 2001 & 2002 & 2003 & 2004 & 2005 & 2006 & 2007 & 2008 & 2009 & 2010 & 2011 & 2012 & 2013 & 2014 & 2015 \\
\hline \multirow{4}{*}{$\begin{array}{c}\text { Novovoronezh } \\
\text { NPP }\end{array}$} & 5SG-1 & 19893 & $\Delta$ & & & & & & & & & & & & & & & $\Delta$ & & \\
\hline & 5SG-2 & 19873 & & & & & & & & & & & & & & & & & & \\
\hline & $5 S G-3$ & 19903 & & & & & & & & & & & & & & & & & & \\
\hline & $5 S G-4$ & 19893 & & & & & & & & & & & & & & & & & & \\
\hline Kalinin NPP & 1SG-3 & no & & & & & & & & & & & & & & & & & & \\
\hline \multirow{4}{*}{ Balakovo NPP } & 1SG-1 & 19903 & & & & & & & & & & & & & & & & & & \\
\hline & $1 \mathrm{SG}-4$ & 19903 & & & & & & & & & & & & & & & & & & \\
\hline & $2 \mathrm{SG}-2$ & 20003 & & & & & & & & & & & & & & & & & & \\
\hline & 4SG-1 & no & & & & & & & & & & & & & & & & & & \\
\hline \multirow{2}{*}{\begin{tabular}{|c|} 
South \\
Ukrainian NPP
\end{tabular}} & 1SG-1 & 19893 & & & & & & & & & & & & & & & & & & \\
\hline & 1SG-2 & 198933 & & & & $\Delta$ & & & & & & & & & & & & & & \\
\hline \multirow{3}{*}{$\begin{array}{c}\text { Zaporozhye } \\
\text { NPP }\end{array}$} & 2SG-1 & 19903 & & & & & & & & & & & & & & & & & & \\
\hline & 2SG-2 & 19903 & & & & & & & & & & & & & & & & & & \\
\hline & 4SG-3 & no & & & & & & & & & & & & & & & & & & \\
\hline
\end{tabular}

Note: $\boldsymbol{\Delta}$ - damage revealed by leak.

A negative assessment of the dynamics of damage in 2010-2014 is too pessimistic, since many of these damages are repeated, that is, after the use of repair technology with through-thickness metal removal and subsequent volume filling by welding. However, the detection of leakage in almost the same place (Figure 4) of through damage to the 5SG-1 hot collector at unit No. 5 of Novovoronezh NPP, first $\sim 9$ years after the replacement of the $\mathrm{SG}$, and then $\sim 15$ years after the repair of this defective zone by welding, shows that the main factors that led to through damage were not identified and eliminated during the period from 1998 to 2013.

In [14], it is erroneously stated that the time before appearance of through-thickness defect in the metal of the 5SG-1 hot collector at unit No. 5 of Novovoronezh NPP was 24 years.

As can be seen from table 1, the damage in the SS\#111 zones is localized mainly in the group of SGs replaced at NPP units due to damage to the headers and/or due to plugging of the heat exchange tubes over the limit. Of the 15 damaged units, only 3 were damaged on SGs operating on the units since installation. Information on SG replacements is provided in the report [15] based on several sources [5, 16-17].

When replacing the SGs on an NPP unit in operation, one of the welded joints SS\#111 of "hot" or "cold" header it becomes the closing one, whereas when installing SG to MCC at construction stage both welded joints SS\#111 of the "hot" and "cold" headers to Dn850 pipelines are never the closing ones.

Thus, it seems acceptable to assume that part of the SGs was installed with the presence of implicit mounting preload during replacement (tables 1 and 2), which was not detected after repair and was not recorded in the reporting documentation. A similar hypothesis about the presence of implicit mounting preload during the installation of part of the SGs in the MCC on newer blocks also seems realistic, since table 1 shows that the percentage of damaged SGs (from the number of not replaced) is significantly lower than among the sample of replaced SGs.
In the future, the presence of implicit mounting preload during the installation/repair could lead to restrictions (jamming) when SG moving via supports, taking into account the specifics of design solutions for MCC of VVER NPP Units of "small" series, and on VVER NPP Units of the project V-320.

Therefore, the main cause of primary cracks in the SS\#111 zones is the interaction of several factors that were excluded earlier from the analysis of the causes of damage in [18], namely: «4.1 Preload of the Du850 MCP during the replacement of the SGs», «4.3. Jammed roller and/or ball bearing supports of $\mathrm{SG}$ and/or $\mathrm{MCC} »$, «4.4 SG jammed for other reasons», which can be combined into a common cause: "shortness (jamming) of SG displacement on the supports". The crack growth rates depend to a significant extent on the conditions of the water chemistry directly in the "pockets" of the SG.

In conclusion, it should be noted the difference in the mechanisms of corrosion-mechanical damage of SS\#23 and SS\#111 and Their impact on the conditions of safe long-term operation:

- damage in the SS\#23 zone along the whole perimeter of circumferential weld could potentially lead to significant consequences of its complete break; therefore, repairing $100 \%$ of the perimeter of the circumferential weld was the only acceptable technical solution;

- primary damage in the SS\#111 zone did not lead to extensive propagation along the circumferential weld perimeter, and the correlation of their location with the "MCC line" indicates the role of mechanical loads in the process of damage that does not pose a threat of complete break; however, for long-term cost-effective operation of the SG, it is necessary to improve the load monitoring system for the SS\#111 zone (for early detection of prerequisites for cracking initiation) and the SG maintenance and repair/replacement technology. 


\section{References}

1. A.E. Korneev, D.S. Zmienko, A.S. Gudenko, Proceedings of the 11th International conference of NPP's young specialists (2009) [in Russian]

2. N.B. Trunov, S.A. Kharchenko, N.F. Korotaev, S.L. Lyakishev, Proceedings of the 8th International seminar of horizontal steam generators (2010) [in Russian]

3. A.E. Korneev, V.D. Khodakov, I.L. Kharina, N.P. Razygraev, Notes on the nature of damage to the metal of primary collector-to-steam generator vessel welding of the steam generator 3SG-1 Novovoronezh NPP (2007) [in Russian]

4. N.P. Zhuk, Course of the theory of corrosion and protection of metals (Metallurgy, Moscow, 1976) [in Russian]

5. B.I. Lukasevich, N.B. Trunov, Yu.G. Dragunov, S.E. Davidenko, Steam generators of VVER reactor plants for nuclear power plants (IKTS "Akademkniga», Moscow, 2004) [in Russian]

6. A.V. Dub, A.N Razygraev, N.P. Razygraev, A.N. Ryabov, I.L. Kharina, Proceedings of the 12th international conference on "Material issues in design, manufacturing and operation of nuclear power plants equipment" (2012) [in Russian]

7. JSC NPO "CNIITMASH", Presentation at the Meeting of Section 3 "Safety of nuclear power facilities" of Scientific and technical Council of Rostehnadzor at 26.12.2015 (2015) [in Russian]

8. L.S. Ojigov and etc, Proceedings of the 8th Conference "Safety Assurance of NPP with VVER" (2013) [in Russian]

9. JSC OKB "GIDROPRESS", Presentation at the Meeting of Section 3 "Safety of nuclear power facilities" of Scientific and technical Council of Rostehnadzor at 26.12.2015 (2015) [in Russian]

10. A.N. Razygraev. Presentation at Working meeting of the WANO Moscow center (2015) [in Russian]

11. A.V. Bogachev, V.P. Semishkin, A.O. Nagorny, A.V. Merkun, D.B. Muravin, R.Yu. Zhukov, E.A. Frizen, Heavy engineering 7-8, 22-28 (2017) [in Russian]

12. SEC NRS, Presentation at the Meeting of Section 3 "Safety of nuclear power facilities" of Scientific and technical Council of Rostehnadzor at 26.12.2015 (2015) [in Russian]

13. WANO MC, Aide-Memoire on the results of the workshop at the Armenian NPP (2015) [in Russian]

14. V.P. Povarov, Nuclear Energy and Technology 1, 1, 68-73 (2015)

15. E.G. Adadurov, M.I. Antonov, A.I. Arzhaev, S.I. Velikodnij, Yu.E. Karyakin, V.O. Makhanev, M.A. Podlatov, Report at the 5th International scientific and technical conference JSC "Atomtechenergo" (2018) [in Russian]

16. A.A. Kadnikov, Optimization of the complex of works on replacement of steam generators of nuclear power units with VVER, Ph. D. diss., Ural State Tech. U. (2009) [in Russian]

17. A.V. Gerasimov, Proceedings of the 8th Conference "Safety, efficiency and economics of nuclear power industry" (2012) [in Russian]

18. A.F. Getman, A.I. Usanov, B.I. Lukasevich, A.A. Tutnov, L.A. Pasmanik, V.A. Smirnov, A.V. Kamyshev, Proceedings of the 8th International seminar of horizontal steam generators (2010) [in Russian] 